\title{
Microstructures and mechanical properties of engineered short fibre reinforced aluminium matrix composites
}

\author{
H.X. Peng ${ }^{a, 1}$, Z. Fan ${ }^{a}$, D.S. Mudher ${ }^{a}$, J.R.G. Evans ${ }^{b, *}$ \\ a Department of Materials Engineering, Brunel University, Uxbridge, Middlesex, UB8 3PH, UK \\ ${ }^{\mathrm{b}}$ Department of Materials, Queen Mary, University of London, Mile End Road, London E1 4NS, UK
}

Received 29 June 2001; received in revised form 5 November 2001

\begin{abstract}
Aluminium matrix composites have been fabricated by squeeze casting into short fibre preforms modified on the basis of a phase contiguity model to improve mechanical performance. Fibre junctions were created in a planar random alumina fibre array by (a) sintering, (b) phosphoric acid treatment, (c) phosphoric acid/aluminium hydroxide $(\mathrm{P} / \mathrm{Al})$ treatment and (d) infiltration with alumina powder and sintering. The microstructures and mechanical properties of these composites were examined systematically. The results indicate that using phosphoric acid solution itself to create inter-fibre bonds in the preform gave rise to very low composite strength and ductility compared with that resulting from the as-received preform. This is mainly due to the severe damage to the fibres caused by chemical reaction. By employing the $\mathrm{P} / \mathrm{Al}$ binder to create the cross-links, the composites reinforced with laboratory-made preforms yielded higher tensile strength relative to the uniform fibre reinforced composites without any sacrifice to the ductility and elastic modulus. (C) 2002 Elsevier Science B.V. All rights reserved.
\end{abstract}

Keywords: Metal matrix composites; Preforms; Alumina fibre

\section{Introduction}

The development of metal matrix composites (MMCs) can be regarded as one of the major innovations in materials in the past 30 years [1] and they have been predicted to find extensive applications in industry [2]. Currently available MMCs are either too brittle (very low damage tolerance) or too expensive to be used in many engineering applications. The successes in exploiting the high strength or modulus of reinforcement are shadowed by the failure to exploit the ductility of the matrix. Many MMC researchers have followed conventional materials outlook and pursued a homogeneous microstructure, perhaps failing to appreciate the unique characteristics of MMCs. Therefore, little effort has been made to tailor the architecture (morphology and spatial distribution) of the reinforcement.

\footnotetext{
* Corresponding author. Tel.: +44-20-7882-5501; fax: +44-208981-9804.

E-mail address: j.r.g.evans@qmul.ac.uk (J.R.G. Evans).

${ }^{1}$ Present address: Department of Materials, University of Oxford, Parks Road, Oxford, OX1 3PH, UK.
}

One of the most economic fabrication methods is liquid-metal infiltration, squeeze casting for instance, in which porous ceramic preforms consisting of short fibres, ceramic whiskers or particles provide the reinforcing phase [3]. In this method, the microstructure of the composite can be controlled by tailoring the preform architecture.

Inspired by the bio-mimetic approach to the design of composite materials, models of short fibre-reinforced composites have been developed [4]. Fibres with enlarged-ends have been proven to be more efficient in strengthening the composite than uniform fibres. This model was adapted by Zhu et al. [5] to fabricate novel composite materials reinforced with bone-shaped short fibres. These exhibited both higher strength and higher fracture toughness compared with those reinforced by uniform fibres. Phan-Thien's work [6,7] also concluded that enlarged-ended fibres considerably increase the strength and fracture toughness of composites compared with those of the same matrix reinforced by uniform fibres with the same physical properties and aspect ratios. This was explained by additional resistance to deformation and pull-out. Investigations sug- 
gested that a composite reinforced with branched fibres could offer greater strength and fracture toughness than composites reinforced with uniform fibres [8,9]. Unfortunately, no practical application of this model for MMCs has been found so far partly because of the processing difficulties. Possible ways to make enlargedended fibre and branched-fibre arrangements are to attach particles to the fibres and to create inter-fibre cross-links, respectively. Such fibre architectures are expected to provide similar contributions to composite strength and toughness.

The role of inter-fibre bonds and the strength of fibre networks have been investigated extensively in the paper industry [10-13]. Poor inter-fibre bonds in the fibre network result in low mechanical strength [14]. Interest in the chemical bonding of ceramics [15] is therefore relevant to the preparation of preforms and such technology is well-reviewed [3]. In this context, phosphoric acid or acid phosphate salts [16] have been used as additives for high-alumina refractories because they impart a strong bond over a wide temperature range up to the point of ceramic sintering. Strong phosphate bonds can be produced by aluminium phosphate or by direct reaction of phosphoric acid to form aluminium phosphate at particle or fibre junctions [17].

A theoretical model based on a microstructural approach allows a range of physical and mechanical properties of composites to be predicted [18-20]. One of the outcomes of this model is that the mechanical and physical properties depend more directly on the continuous volume fraction of reinforcement than on the overall volume fraction. This offers sufficient justification to explore the property advantages that are expected to accrue from modifying the fibre arrangement to give controlled inhomogeneous structures in MMCs $[21,22]$.

The objective of this work is to investigate experimentally the effects of different fibre structures on the mechanical properties of MMCs fabricated by melt infiltration of preforms. This forms part of our investigation into so-called second generation MMCs in which the architectures of reinforcement play key roles in influencing properties. The following fibre architectures were developed: sintering of uniform fibres in the

Table 1

Properties of the SAFFIL alumina fibre (RF grade)

\begin{tabular}{ll}
\hline Chemical composition & $\mathrm{Al}_{2} \mathrm{O}_{3}: 96-97 \%$ \\
& $\mathrm{SiO}_{2}: 3-4 \%$ \\
Crystal phase & $\mathrm{Mainly} \delta$-alumina $^{\mathrm{a}}$ \\
Density & $3300 \mathrm{~kg} \mathrm{~m}^{-3}$ \\
Median fibre diameter & $3 \mu \mathrm{m}$ \\
Melting point & $>2000{ }^{\circ} \mathrm{C}$ \\
Tensile strength & $2000 \mathrm{MPa}$ \\
Young's modulus & $300 \mathrm{GPa}$
\end{tabular}

a $\alpha$-Alumina $<15 \%$, as claimed by the manufacturer. as-received preform, cross-linking of fibres created by preform modification using phosphate binders and particle infiltrated fibre assemblies. This paper describes an experimental investigation of the microstructure and mechanical properties of MMCs fabricated by such engineered fibrous preforms.

\section{Experimental details}

\subsection{Materials}

SAFFIL $^{\mathrm{TM}}$ (ex ICI, UK) alumina short fibre and the preforms made therefrom were provided by Vernaware (Bolton, UK). The preforms have relative densities, defined as apparent density expressed as a percentage of the theoretical density of the preform material, of 10 and $20 \%$ and dimensions of $65 \mathrm{~mm}$ diameter and 25 $\mathrm{mm}$ height. Table 1 gives the fibre properties. Phosphoric acid with a concentration of $85 \mathrm{wt} . \%$ and aluminium hydroxide with an assay of $64-66$ wt. $\% \mathrm{Al}_{2} \mathrm{O}_{3}$ were used to prepare the binder solutions. The matrix material used for the fabrication of the composites was 6061 aluminium alloy with $(0.8-1.2)$ wt.\% $\mathrm{Mg},(0.4-0.6)$ wt.\% Si supplied by EMS (Uxbridge, Middlesex, UK). This alloy has liquidus and solidus temperatures of 650 and $582{ }^{\circ} \mathrm{C}$, respectively.

\subsection{Methods to create inter-fibre bonds}

In an attempt to enhance the strength of the contact points, the as-received preforms were sintered at 1200 and $1650{ }^{\circ} \mathrm{C}$ for $2 \mathrm{~h}$ with a heating rate of $10{ }^{\circ} \mathrm{C} \mathrm{min}{ }^{-1}$. In subsequent experiments, the sintering times at $1200{ }^{\circ} \mathrm{C}$ were extended to 4 and $6 \mathrm{~h}$ while those at $1650{ }^{\circ} \mathrm{C}$ were shortened to 1 and $0.5 \mathrm{~h}$.

Phosphoric acid solutions at dilutions of 1:2 and 1:10 by volume were prepared to produce different amounts of aluminium phosphate binder after reaction with $\mathrm{Al}_{2} \mathrm{O}_{3}$ fibre. The preforms were immersed in the solution gradually. After drying at $200{ }^{\circ} \mathrm{C}$ for $24 \mathrm{~h}$, they were sintered at either 800,1000 or $1200{ }^{\circ} \mathrm{C}$ for $4 \mathrm{~h}$. The lowest temperature was $800{ }^{\circ} \mathrm{C}$ because the melt infiltration temperature is about $800{ }^{\circ} \mathrm{C}$.

Phosphoric acid and aluminium hydroxide were used to make an aluminium phosphate binder with a $\mathrm{P} / \mathrm{Al}$ atom ratio of 3 and a concentration of 1 part phosphate binder to 10 parts of distilled water by volume. On immersion this gave $6 \mathrm{wt} . \%$ binder in the 10 vol. $\%$ preform. After drying at $200{ }^{\circ} \mathrm{C}$ for $24 \mathrm{~h}$ the preforms were calcined at $800{ }^{\circ} \mathrm{C}$ for $2 \mathrm{~h}$.

In order to exclude the influences of added silica and of the sintering procedure in the as-received performs, preforms with the same volume fraction were made in this laboratory using the identical fibre and filter-pressing method as used by Vernaware. The as-received 
SAFFIL short fibres were mixed thoroughly with the $\mathrm{P} / \mathrm{Al}$ phosphate solution and then poured into an aluminium cylindrical die with a filter at the base. When the liquid had nearly vanished from the top, a wellfitting ram was placed on the top to apply pressure to obtain a given fibre volume fraction. After drying at $200{ }^{\circ} \mathrm{C}$ for $24 \mathrm{~h}$, the preforms were calcined at $800{ }^{\circ} \mathrm{C}$ for $2 \mathrm{~h}$. These lab-made preforms had the same dimensions as those of the as-received preforms.

As-received SAFFIL preforms were infiltrated with fine alumina powder suspension. Alcan RA45E grade alumina powder with $d_{50}$ of $0.48 \mu \mathrm{m}$ was donated by Alcan Chemicals (Gerrards Cross, UK) and was used to prepare a suspension containing 2.5 vol. $\%$ particles. After infiltration, they were dried at $200{ }^{\circ} \mathrm{C}$ for at least $12 \mathrm{~h}$ and then sintered at $1200{ }^{\circ} \mathrm{C}$ for $2 \mathrm{~h}$ with the intention of sintering the particles onto the fibre surface without fibre deterioration. In order to prepare suspensions for infiltration, sedimentation tests were carried out on 5 vol. \% alumina suspensions adjusted to $\mathrm{pH} 1.7$, 8.5 and 12 as measured by a model PW9418 pH meter (Philips, UK) calibrated with a $\mathrm{pH} 4$ buffer. The suspension exhibiting the longest sedimentation time $(\mathrm{pH}=12)$ was chosen for the preform infiltration.

Microstructures of all preforms were examined using a JEOL JAX840 scanning electron microscope. Phases formed during sintering were identified by X-ray-diffraction (XRD). The compressive strength of the preforms was measured using a Model 4206 Instron testing machine (Instron Ltd, Buckinghamshire, UK) fitted with flat steel platens closing with a cross-head speed of $0.5 \mathrm{~mm} \mathrm{~min}^{-1}$. Samples with rectangular shape and approximate size of $20 \times 20 \times 30 \mathrm{~mm}^{3}$ were cut from the preform cylinders. In the planar-random arrangement of as-received preforms, samples were tested along the direction perpendicular to the axial direction of the cylinder and at least three samples were tested for one condition to provide average values.

\subsection{Composite fabrication and microstructural characterisation}

MMCs were fabricated by squeeze casting with a $500 \sim 550{ }^{\circ} \mathrm{C}$ preheat. The alloy was poured at $800{ }^{\circ} \mathrm{C}$ at an approximate rate of $5 \times 10^{-5} \mathrm{~m}^{3} \mathrm{~s}^{-1}$ and a ram, activated by a 25 tonne hydraulic press, forced the melt into the preform while evacuation was applied. After infiltration, a maximum pressure of $50 \mathrm{MPa}$ was maintained until the die cooled and the aluminium phase solidified. The cast cylindrical billets were polished on the sides and examined using an optical microscope to obtain the composite height. This gave the preform deformation caused by the infiltration from which the reinforcement volume fraction $\left(V_{\mathrm{f}}\right)$ was determined. The deformation of the preform was assured to be less than $2 \%$. This is particularly important for the preform with bonded inter-fibre links since large preform deformation may cause fracture of the inter-fibre bonds. The microstructures of the composites were examined in a JEOL JXA840 scanning electron microscope.

\subsection{Mechanical testing}

Tensile testing was performed on as-cast MMCs at room temperature using a Model 4206 Instron testing machine (Instron Ltd, Buckinghamshire, UK) at a constant cross-head speed of $0.5 \mathrm{~mm} \mathrm{~min}{ }^{-1}$. The test bars were obtained by cutting the as-cast composite cylinder parallel to the cylindrical axis to form a plate with 6 $\mathrm{mm}$ width and then slicing to $2 \mathrm{~mm}$ thickness to give a final sample dimension of about $55 \mathrm{~mm} \times 6 \mathrm{~mm} \times 2$ $\mathrm{mm}$. These pieces were polished to eliminate cutting damage to the surfaces and then two aluminium terminals were attached to both sides of the sample ends using ARALDITE 421 epoxy resin (Ciba Speciality Chemicals, Duxford, Cambridge, UK) for griping purposes. Strain gauges (Type: EP-08-250BG-120, supplied by the Measurement Group UK Ltd, Basingstoke, Hampshire) were used to measure the elongation. Strain gauges were attached on one side $(6 \times 55 \mathrm{~mm})$ of the sample using M-Bond AE-10 adhesive (supplied ibidem) and following the standard procedure developed by the Measurement Group [23]. These strain gauges are temperature-compensated. The samples failed within the gauge length with no indications of slippage in the grips or debonding.

Resonant vibration in flexural mode was used to measure elastic modulus. A HP 35665A Dynamic Signal Analyzer was employed to detect the fundamental resonance frequencies. The modulus was deduced using the EMOD programme (J.W. Lemmens Inc., USA). Samples with approximate dimensions of $2 \mathrm{~mm} \times 6$ $\mathrm{mm} \times 50 \mathrm{~mm}$ rested on nodes at about $\mathrm{L} / 4$ from each end and were set in vibration by striking the sample with ceramic projectiles. The aspect ratio is 25 and so according to ASTM:C1259, the results reflect the modulus in the longitudinal direction.

\section{Results and discussion}

\subsection{Sintered preforms}

Fig. 1 shows the microstructure of the as-received SAFFIL preform. According to the manufacturer's information, it contained a small amount of silica binder and was fired at $1150{ }^{\circ} \mathrm{C}$ for $1 \mathrm{~h}$. Traces of $\mathrm{SiO}_{2}$ exist either on the fibre surface or around the fibre contact points. The latter enhance preform strength but Fig. 1 also shows that the number density of such contact points is itself low. 


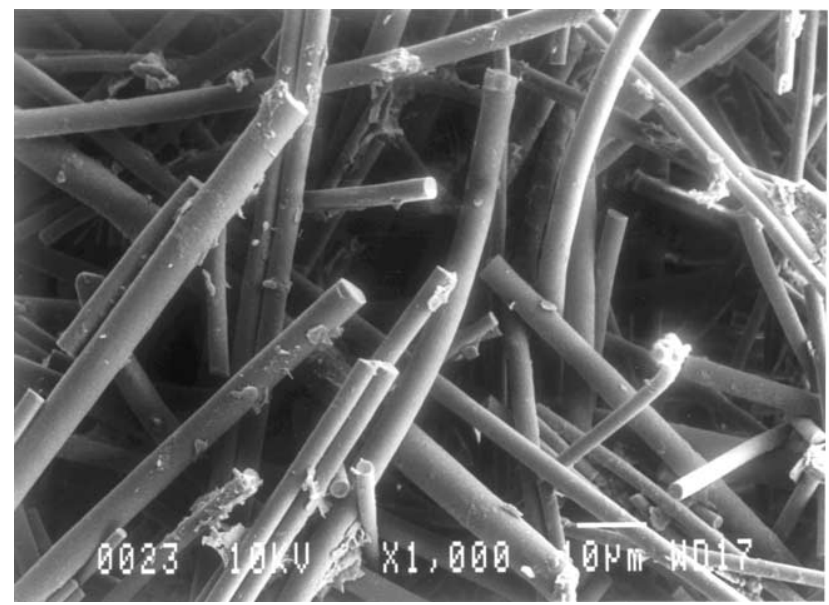

Fig. 1. Microstructure of the as-received preform showing the fibre morphology.

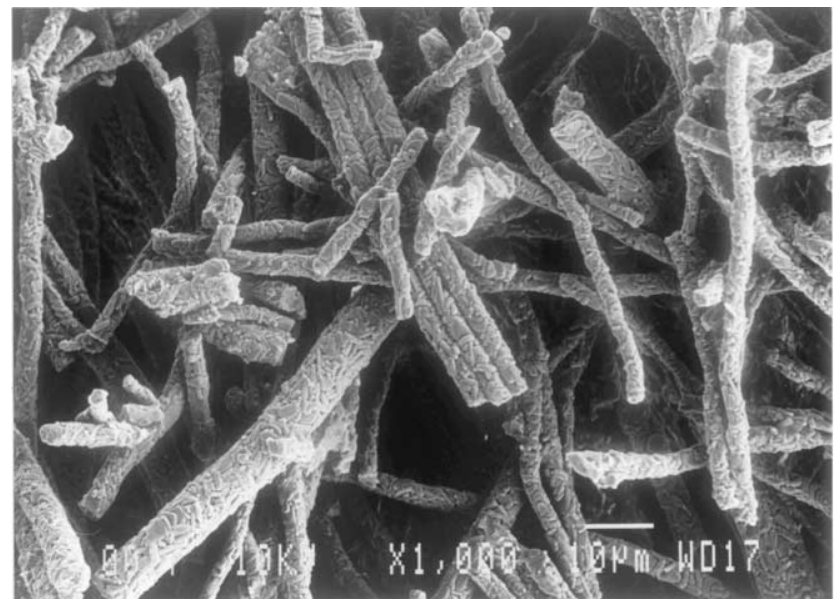

Fig. 2. Fibre morphology in the preform after sintering at $1650{ }^{\circ} \mathrm{C}$ for $2 \mathrm{~h}$.

Table 2

Volumetric changes of the as-received preforms after high temperature sintering

\begin{tabular}{llll}
\hline $\begin{array}{l}\text { Temperature } \\
\left({ }^{\circ} \mathrm{C}\right)\end{array}$ & $\begin{array}{l}\text { Volume } \\
\text { fraction }(\%)\end{array}$ & \multicolumn{2}{l}{ Volumetric shrinkage $(\%)$} \\
\cline { 3 - 4 } & & Sintering 2 h & Sintering 4 h \\
\hline 1200 & 10 & 0.8 & 1.8 \\
& 20 & 0.2 & 1.5 \\
1650 & 10 & 18.0 & 19.9 \\
& 20 & 17.7 & 18.8 \\
\hline
\end{tabular}

After sintering at $1200{ }^{\circ} \mathrm{C}$, the morphology is retained but there is little enhanced sintering at the fibre contact points. Sintering at $1650{ }^{\circ} \mathrm{C}$ for $2 \mathrm{~h}$ caused nucleation and growth of the $\alpha$-alumina phase (Fig. 2) but fibres have been sintered together at the contact points. The grain size of the $\alpha$-alumina is several microns, much larger than the original grain size of about
$50 \mathrm{~nm}$ [24]. Unfortunately, previous studies [24,25] indicated that this transformation caused the tensile strength to decrease dramatically leading to less reinforcing efficiency in the resulting composites. The preforms sintered at $1200{ }^{\circ} \mathrm{C}$ for 4 and $6 \mathrm{~h}$ appeared similar to those sintered for $2 \mathrm{~h}$. Sintering at $1650{ }^{\circ} \mathrm{C}$ for 1 and $0.5 \mathrm{~h}$ gave similar micrographs to those sintered for $2 \mathrm{~h}$.

The volumetric changes of the preforms before and after sintering were monitored by measuring the dimensions with a micrometer having an accuracy of $0.01 \mathrm{~mm}$ (Table 2). Significant volumetric shrinkage ( 18\%) was noted in preforms sintered at $1650{ }^{\circ} \mathrm{C}$ while sintering at $1200{ }^{\circ} \mathrm{C}$ caused only $0.2 \sim 1.8 \%$ shrinkage. The preform with a fibre volume fraction of $20 \%$ gave less shrinkage than that of the $10 \%$ preform. Slight changes can be attributed to attrition during handling so the values in Table 2 are upper estimates. The large volume shrinkage on sintering at $1650{ }^{\circ} \mathrm{C}(\sim 18 \%)$ is mainly due to the density variation from $\delta$-alumina $(3300$ $\mathrm{kg} \mathrm{m}^{-3}$ ) to $\alpha$-alumina (3987 $\mathrm{kg} \mathrm{m}^{-3}$ ) as revealed by $\mathrm{XRD}$ and results in a theoretical volume shrinkage of $17.2 \%$.
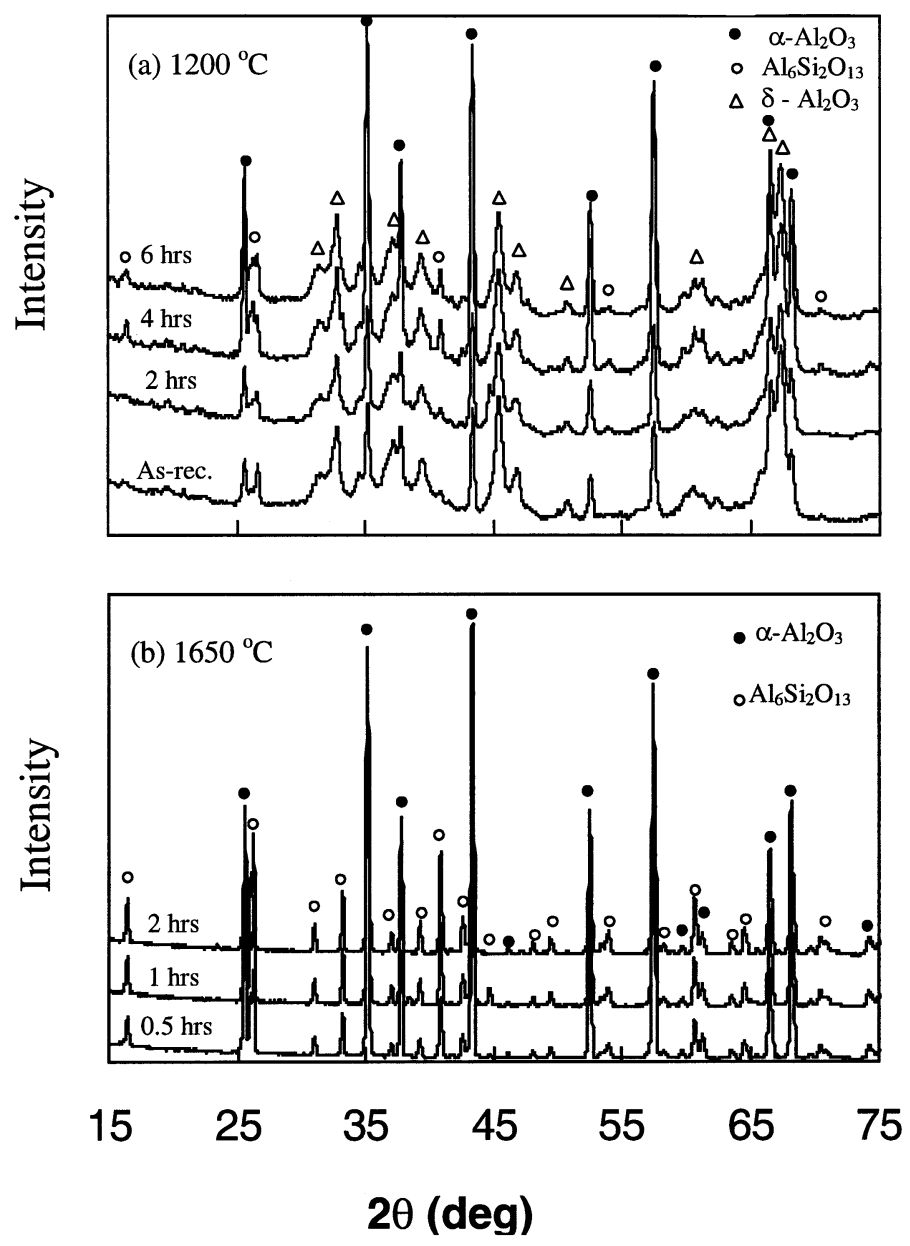

Fig. 3. XRD traces of the preforms sintered at (a) $1200{ }^{\circ} \mathrm{C}$ and (b) $1650{ }^{\circ} \mathrm{C}$ for different times. 
Table 3

Volume and weight changes and compressive strength of the $20 \mathrm{vol} . \%$ as-received preforms after modification with 1:2 phosphoric acid solution

\begin{tabular}{lllll}
\hline Modification & & Volume change $(\%)$ & Weight change $(\%)$ & Compressive strength (MPa) \\
\hline Drying & $200{ }^{\circ} \mathrm{C}, 24 \mathrm{~h}$ & $-0.3( \pm 0.05)$ & $+37.5( \pm 0.1)$ & - \\
Sintering & $800{ }^{\circ} \mathrm{C}, 4 \mathrm{~h}$ & -0.13 & +31.5 & 35.3 \\
& $1000{ }^{\circ} \mathrm{C}, 4 \mathrm{~h}$ & -0.2 & +30.2 & 15.9 \\
& $1200{ }^{\circ} \mathrm{C}, 4 \mathrm{~h}$ & -1.1 & +30.7 & 10.1 \\
\hline
\end{tabular}

The XRD results (Fig. 3a and b) show that the as-received preform is composed of mainly $\delta$-alumina with minor amount of $\alpha$-alumina and $\mathrm{Al}_{6} \mathrm{Si}_{2} \mathrm{O}_{13}$. The peaks are not sharp due to the fine-grained structure [24]. The peak intensities of the $\alpha$-alumina increased slightly after sintering at $1200{ }^{\circ} \mathrm{C}$ for $2 \mathrm{~h}$, and correspondingly, those of the $\delta$-alumina decreased (Fig. 3b) suggesting partial phase transformation from $\delta$ - to $\alpha$ alumina occurred at $1200{ }^{\circ} \mathrm{C}$, in agreement with our previous work [22]. Increased sintering time had limited effect on the phase transformation. There are a few peaks corresponding to $\mathrm{Al}_{6} \mathrm{Si}_{2} \mathrm{O}_{13}$, which appeared after heat treatment at $1200{ }^{\circ} \mathrm{C}$, due to the reaction between $\mathrm{Al}_{2} \mathrm{O}_{3}$ and $\mathrm{SiO}_{2}$. There are two sources of $\mathrm{SiO}_{2}$, one is SAFFIL fibre itself (Table 1), the other is the additions made during preform manufacturing. After sintering at $1650{ }^{\circ} \mathrm{C}$ for $0.5 \mathrm{~h}$, the transformation of $\delta$ - to $\alpha$-alumina went to completion and the peaks of $\alpha$-alumina were very sharp due to extensive increase in grain size. The peaks of $\mathrm{Al}_{6} \mathrm{Si}_{2} \mathrm{O}_{13}$ were also well defined (Fig. 3b). There was little difference in the XRD traces for different sintering times.

Compression tests on sintered preforms indicated that the strength of the preform (20 vol.\% fibre) sintered at $1200{ }^{\circ} \mathrm{C}$ was slightly higher $(2.4 \mathrm{MPa})$ than the as-received preform $(2.0 \mathrm{MPa})$ which had already been sintered at $1150{ }^{\circ} \mathrm{C}$ during manufacture. The preform sintered at $1650{ }^{\circ} \mathrm{C}$ gave a strength of about $10 \mathrm{MPa}$ partly because of the higher relative density caused by the shrinkage and the stronger bonding at fibre contact points and in spite of fibre strength degradation.

The ineffectiveness of sintering to strengthen interfibre contact points at lower temperature $\left(1200{ }^{\circ} \mathrm{C}\right)$ and the severe fibre degradation that occurred at higher temperature $\left(1650{ }^{\circ} \mathrm{C}\right)$ suggest that sintering of performs may not be an ideal way to strengthen the composites.

\subsection{Phosphoric acid treatment}

Chiou and Chung's work [26] suggests that phosphoric acid alone can serve as a binder by reaction with $\mathrm{Al}_{2} \mathrm{O}_{3}$ fibre. Their treatment was carried out (Section 2.2) followed by sintering at 800,1000 and $1200{ }^{\circ} \mathrm{C}$ to minimise the phase transformation. The volume and weight changes of these preforms $(20$ vol. $\%$ modified with 1:2 acid solution) before and after sintering are listed in Table 3. Drying at $200{ }^{\circ} \mathrm{C}$ exerted negligible influence on the preform volume, as did sintering at 800 and $1000{ }^{\circ} \mathrm{C}$. Sintering at $1200{ }^{\circ} \mathrm{C}$ gave a $1.1 \%$ shrinkage. The phosphate binder increased the mass of the preform by $37 \%$ after drying, reduced to about $31 \%$ after calcination at $800{ }^{\circ} \mathrm{C}$. Sintering at 1000 and $1200{ }^{\circ} \mathrm{C}$ resulted in a relatively larger weight loss than that recorded at $800{ }^{\circ} \mathrm{C}$. This is possibly due to the dissociation of aluminium metaphosphate, $\mathrm{Al}\left(\mathrm{PO}_{3}\right)_{3}$, to aluminium orthophosphate, $\mathrm{AlPO}_{4}$, as indicated by XRD patterns presented below. The large amount of binder (Table 3 ) is due to the high concentration of the acid. The concentration was therefore adjusted to 1:10 by volume to give a mass increment of about $6 \%$.

The microstructure of a fibre preform (20 vol.\%) after modification with phosphoric acid solution (1:2 ratio) and sintering at $800{ }^{\circ} \mathrm{C}$ for $4 \mathrm{~h}$ is shown in Fig. 4. Fibres are bonded together to form cross-links and the binder is intact and smooth. Lower magnification observations revealed a three-dimensionally bonded fibre network. Modification with a lower acid concentration solution (ratio 1:10) resulted in less binder on the surface of fibres and at fibre junctions. SEM observations indicated that there was little difference in the binder distribution between the centre region (within a half radius of the cylinder) and the outer layer of the preform except on the surface of the circular edge of the preform where the binder had a higher volume fraction.

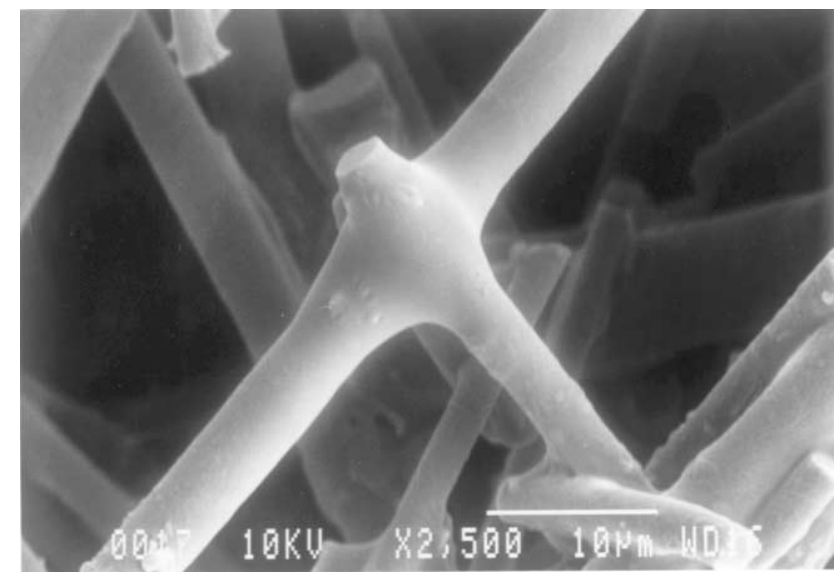

Fig. 4. Fibre morphology in the preform modified with phosphoric acid solution (1:2 ratio) and sintering at $800{ }^{\circ} \mathrm{C}$ for $4 \mathrm{~h}$. 


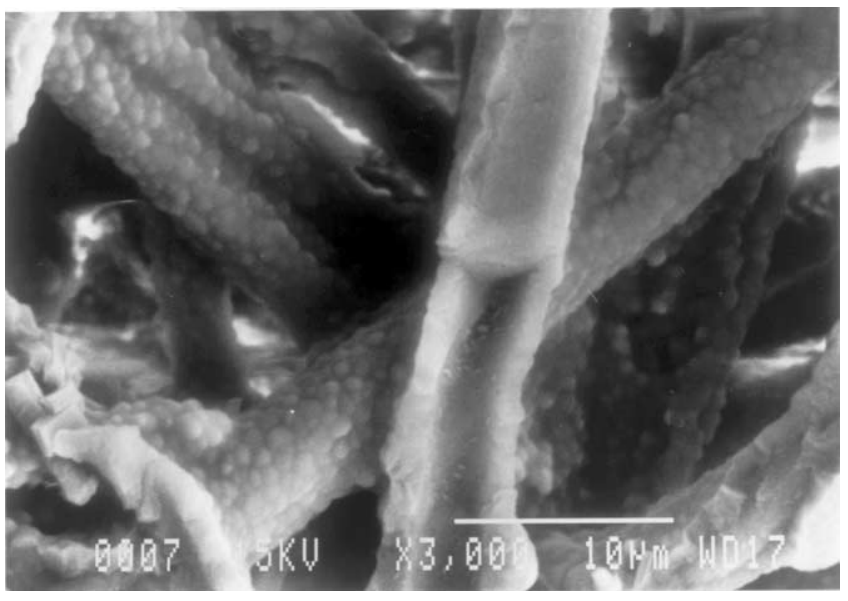

Fig. 5. The morphology of the fibres in the acid-treated preform after sintering at $1200{ }^{\circ} \mathrm{C}$ for $4 \mathrm{~h}$.

The treated preform sintered at $1200{ }^{\circ} \mathrm{C}$ for $4 \mathrm{~h}$ had inter-fibre bonds but severe damage to the fibres (Fig. 5). The acid reacts with the fibre to form a coating and this outer reaction layer appears to be very fragile. The fibre surface under this layer is rough due to the reaction between the acid and the fibre. In Fig. 5 a broken fibre has an outer shell which confirms the reaction. This is likely to be harmful to the strength and reinforcing efficiency. The binder was fragmented after higher temperature sintering; the surface was rough with a particle-like morphology.

Different sintering temperatures resulted in different products as indicated by XRD traces (Fig. 6). Compared with Fig. 6a, sintering at $800{ }^{\circ} \mathrm{C}$ (Fig. 6b) gave a very complicated XRD trace where the peaks are referred to aluminium metaphosphate, $\mathrm{Al}\left(\mathrm{PO}_{3}\right)_{3}$ type $\mathrm{A}$ and type $\mathrm{B}$ besides the $\alpha$ - and $\delta$-alumina. The aluminium silicate $\mathrm{Al}_{6} \mathrm{Si}_{2} \mathrm{O}_{13}$, which appeared in Fig. 6a was not detected because the small amount was screened by the coating. Comparing Fig. $6 \mathrm{c}$ and d, it can be seen that sintering at 1000 and $1200{ }^{\circ} \mathrm{C}$ gave nearly the same XRD pattern except that, in the case of $1200{ }^{\circ} \mathrm{C}$, the peaks of $\mathrm{Al}_{2} \mathrm{O}_{3}$ (both $\alpha$ and $\delta$ ) are more pronounced compared to Fig. 6a. This is due to less binder formation on the fibre surfaces because of the lower concentration of the acid solution (1:10). The dominant binder phase is $\mathrm{AlPO}_{4}$ together with some type $\mathrm{A} \mathrm{Al}\left(\mathrm{PO}_{3}\right)_{3}$. Because of the original solution concentration, the $\mathrm{AlPO}_{4}$ peaks are more notable in Fig. $6 \mathrm{c}$ than that in Fig. 6d. Fig. $6 \mathrm{c}$ and $\mathrm{d}$ shows that the $\mathrm{AlPO}_{4}$ formed instead of $\mathrm{Al}\left(\mathrm{PO}_{3}\right)_{3}$ type $\mathrm{B}$ which is shown in Fig. $6 \mathrm{~b}$ because higher temperature favours the formation of $\mathrm{AlPO}_{4}$ [3].

The measured compressive strengths of the preforms (20 vol.\%) are compared in Table 3. The strength of the as-received preform is relatively low $(2.0 \mathrm{MPa})$ because of the low number density of inter-fibre bonds (Fig. 1) but this is an acceptable strength for squeeze casting. After sintering at $800{ }^{\circ} \mathrm{C}$, the strength was $35 \mathrm{MPa}$, mainly as a result of the increased strength of existing fibre junctions.

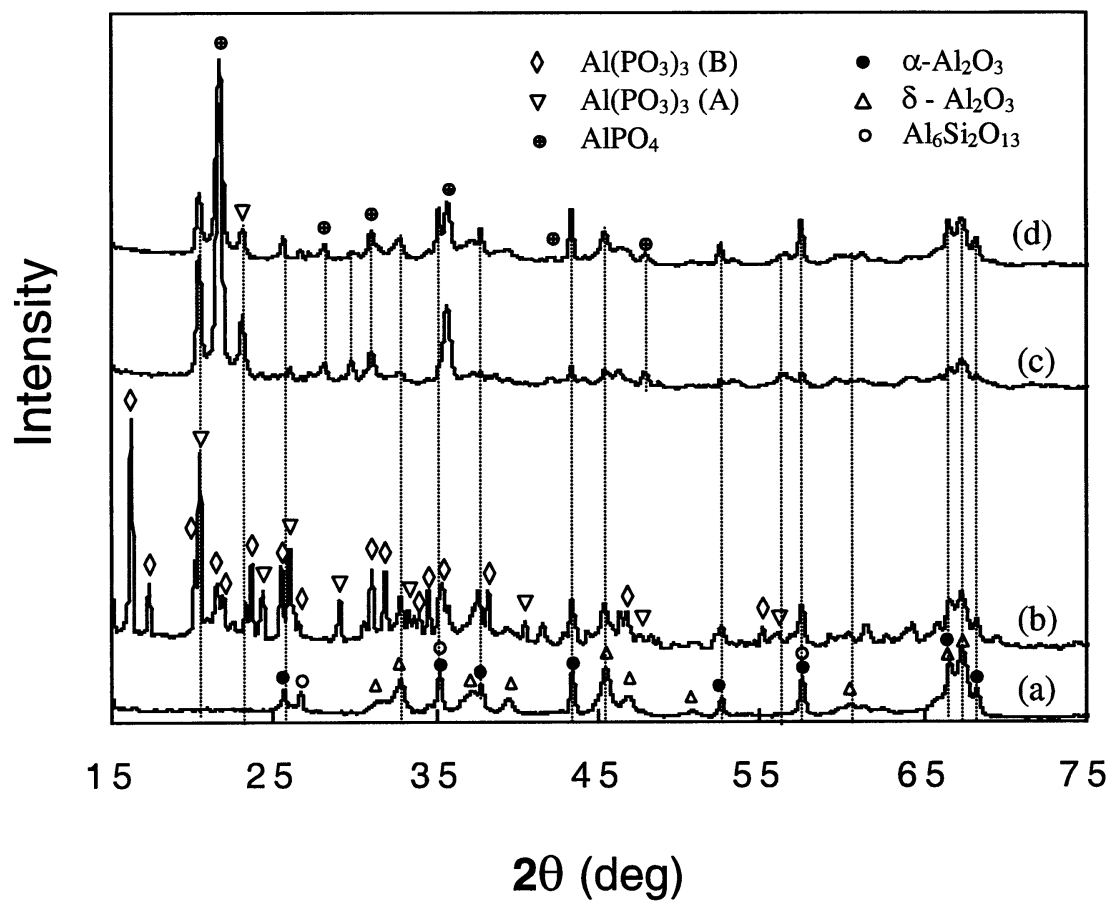

Fig. 6. XRD traces of the as-received and modified preforms with phosphoric acid solution: (a) as-received; (b) $1: 2$ ratio solution, $800{ }^{\circ} \mathrm{C}$; (c) $1: 2$ ratio solution, $1000{ }^{\circ} \mathrm{C}$; and (d) $1: 10$ solution, $1200{ }^{\circ} \mathrm{C}$. 


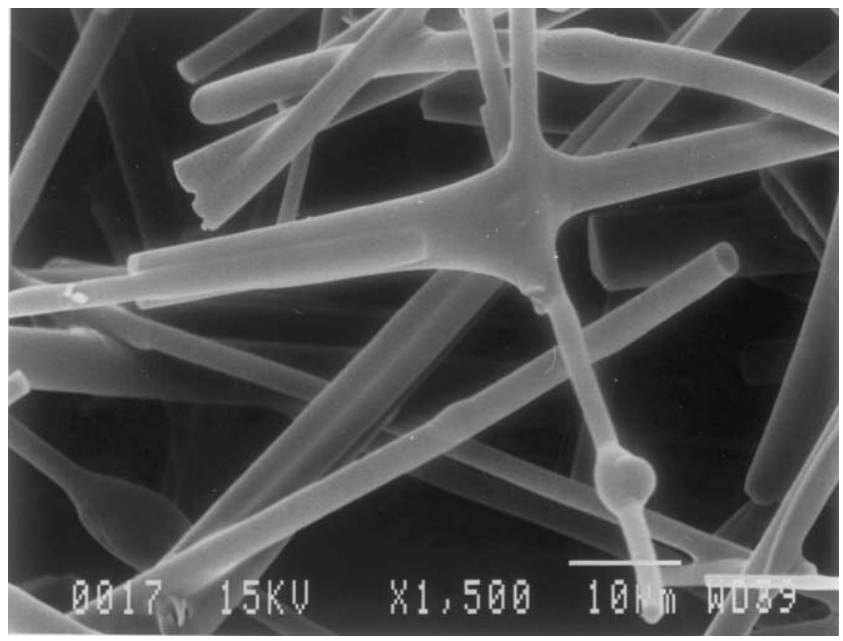

Fig. 7. Typical SEM micrograph of the lab-made preform after drying at $200{ }^{\circ} \mathrm{C}$ for $24 \mathrm{~h}$.

As predicted by a theoretical model [18-20], the mechanical and physical properties of composites depend more directly on the continuous volume fraction of reinforcement than on the overall volume fraction. In a fibre network, two parameters characterising the continuous volume fraction are the free fibre segment length and the number density of fibre-to-fibre contacts and they can be evaluated from the model of Komori and Makishima [27]. The free fibre segment length $(s)$ between fibre-to-fibre contacts can, in terms of that model, be expressed as:

$s=\frac{2 V}{\pi d l_{\text {tot }}}$

where $s$ is the free fibre segment length $(\mathrm{m}), V$ is the volume of network $\left(\mathrm{m}^{3}\right), d$ is the fibre diameter $(\mathrm{m})$ and $l_{\text {tot }}$ is the total length of fibres in the volume $V(\mathrm{~m})$.

Taking the fibre volume fraction as $V_{\mathrm{f}}, s$ can be expressed as:

$s=\frac{d}{2 V_{\mathrm{f}}}$

and the total fibre-to-fibre contacts per unit volume as:

$n=\frac{4 V_{\mathrm{f}}^{2}}{\pi d^{3}}$

From Eqs. (2) and (3), it can be seen that, in a randomly oriented fibre network, the free fibre segment length and the total fibre-to-fibre contacts per unit volume are functions of the volume fraction $\left(V_{\mathrm{f}}\right)$ and fibre diameter $(d)$. The number density of contacts will enable the evaluation of fibre network properties once the properties of the inter-fibre bonds become available. In the present study, preform modifications do not affect the contact number, but they do affect the interfibre bonding strength and hence the overall properties of the network.
At higher sintering temperature, the compressive strength decreased due mainly to fibre degradation by phase transformation and grain growth [22]. Another factor causing the difference in strength is the integrity of the binder; sintering at temperatures above $800{ }^{\circ} \mathrm{C}$ produced fragmented binder. The properties of the reaction products at different temperatures also affect the bonding strength and warrant further investigation.

\subsection{Phosphoric acid/aluminium hydroxide binders}

In Chiou and Chung's work, a binder with a $\mathrm{P} / \mathrm{Al}$ atom ratio of 23 was considered the best for silicon carbide whisker reinforced aluminium composites [26]. In the present work, since excessive acid may react with the $\mathrm{Al}_{2} \mathrm{O}_{3}$ fibre and the reinforcement may deteriorate, aluminium hydroxide was used in conjunction with the acid with a $\mathrm{P} / \mathrm{Al}$ atom ratio of 3 . The sintering temperature selected was $800{ }^{\circ} \mathrm{C}$ to produce aluminium metaphosphate $\mathrm{Al}\left(\mathrm{PO}_{3}\right)_{3}$ reported to be a good hightemperature binder [28] at least up to $1000{ }^{\circ} \mathrm{C}$. Above $1000{ }^{\circ} \mathrm{C}$, it may dissociate to form $\mathrm{AlPO}_{4}$ which is less desirable in terms of binding strength.

The dried and sintered lab-made preform is shown in Fig. 7. Sound inter-fibre cross-links were achieved. The binder was integrated and had a smooth surface. It is noteworthy that some dumb-bell like binder deposits were formed on the fibres. These are believed to be beneficial to the reinforcing effect as demonstrated by enlarged-end fibres [5]. The binder mainly segregated in pendular form to the junctions to form a sound bond and, away from the junctions, there was little binder on the fibre surface.

XRD analysis confirmed that the binder products were mainly aluminium metaphosphate $\mathrm{Al}\left(\mathrm{PO}_{3}\right)_{3}$ type A together with small amount of $\mathrm{Al}\left(\mathrm{PO}_{3}\right)_{3}$ type $\mathrm{B}$. The undesirable $\mathrm{AlPO}_{4}$ was not detected.

\subsection{Powder infiltration}

In the preform modified by infiltration with alumina particles from suspension, the fine particles could be seen both at fibre junctions and attached to the fibre surfaces. There was little sintering between the particles and the fibres because of the relatively low sintering temperature chosen to avoid fibre damage.

\subsection{Characterization of composites made from modified fibre preforms}

Fig. 8 shows an optical micrograph of a composite made from the as-received preform. Similar homogeneity of fibre distribution and freedom from porosity were seen for composites made from modified preforms.

The ultimate tensile strength (UTS), strain to break and elastic modulus of the composites are given in 


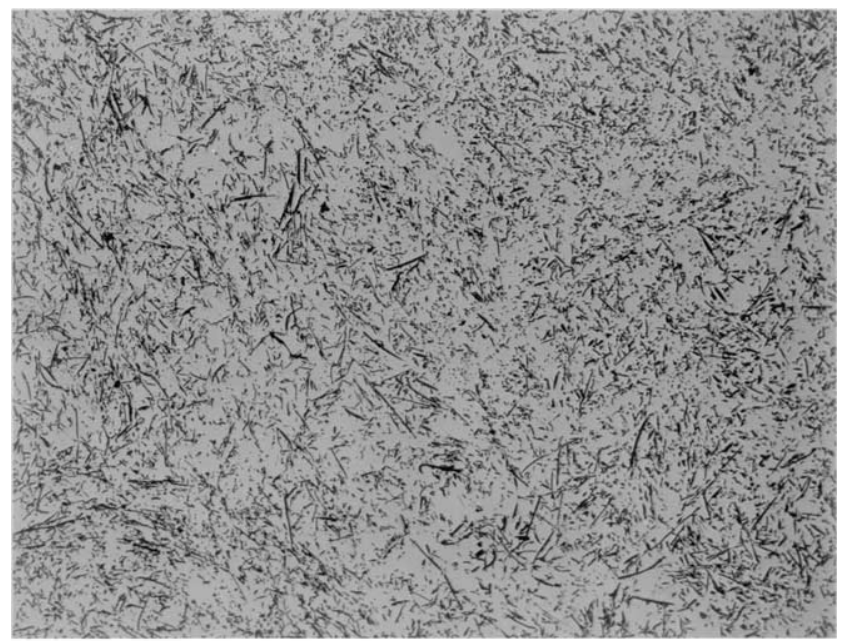

\section{0um}

Fig. 8. Optical micrograph of the composites made from as-received preform $\left(V_{\mathrm{f}}=20 \%\right)$.

Table 4. The preforms present a planar random fibre array and this is preserved in the composite. Since the aspect ratio of bars used for modulus measurement is 25 , the value recorded represents the modulus in this plane. Acid-modification resulted in very low composite strength and strain to break compared with the as-received preform despite showing a high preform compressive strength. Thus using phosphoric acid alone as the binder for alumina fibres as suggested by Chiou and Chung [26] is not always a good choice. Clearly preform strength does not give a guide to the composite properties in the present study.

Modification with $\mathrm{P} / \mathrm{Al}$ solution (Table 4) gave 5\% higher UTS, 28\% lower elongation and 4\% higher modulus while the lab-made preform yielded a $9 \%$ higher UTS without any sacrifice to the ductility and elastic modulus. The mixture provides stoichiometry and so there is no residual acid to react with the reinforcing fibres. The fibres thus remain intact and retain their morphology after modification. The amount of binder seems appropriate; these well-bonded fibres are efficient in load bearing and may be more

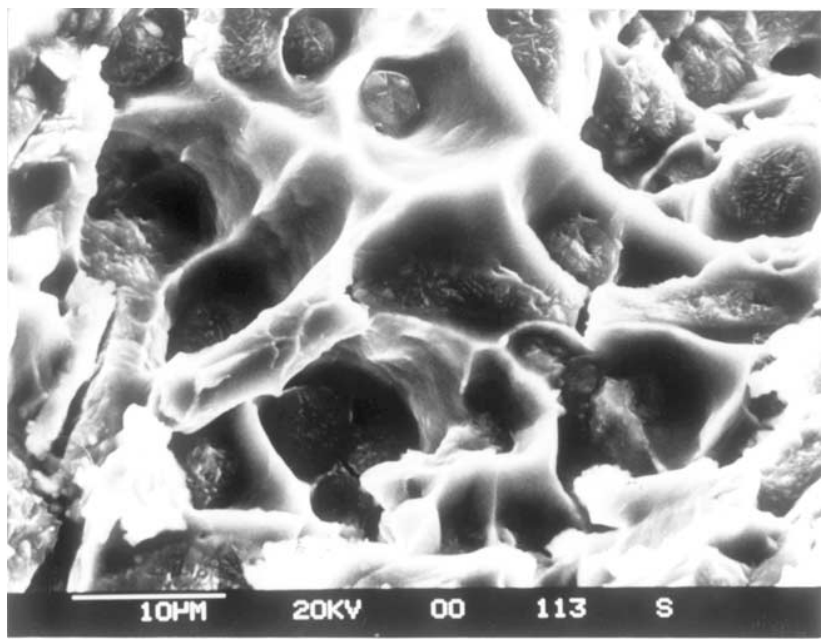

Fig. 9. The fracture surface of the composite made from the preform $\left(V_{\mathrm{f}}=10 \%\right)$ modified by the $\mathrm{P} / \mathrm{Al}$ binder.

resistant to pull out. Indeed the fracture surfaces of these composites indicated fewer fibre pull-outs (Fig. 9). The well-bonded fibres may cause more extensive matrix deformation during the plastic stage and this deformation can be spread throughout the whole sample giving higher ductility as observed in the lab-made preform reinforced composite. A stress model recently proposed for single bone-shaped short fibre composites by Beyerlein et al. [29] provides some insight into the composite behaviour obtained in the present study. However, as recognised by the authors, the local stress state and failure processes involved in well-bonded fibre composites under load are substantially different from those active in single fibre composites.

The microstructure of the composite made from the as-received preform $\left(V_{\mathrm{f}}=20 \%\right)$ modified by particle infiltration is shown in Fig. 10. The particles are mainly distributed near the fibres to form a particle/fibre hybrid MMC. As discussed above, the particles are not well sintered onto the fibre surfaces. The tensile testing results (Table 4) indicated that this hybrid composite possessed higher strength and modulus relative to the MMC reinforced with as-received preform but this was

Table 4

Mechanical properties of the composites made from preforms $\left(V_{\mathrm{f}}=10 \mathrm{vol} . \%\right.$ unless specified) under different modification conditions

\begin{tabular}{|c|c|c|c|}
\hline Preform condition & UTS (MPa) & Strain to break $(\%)$ & Modulus $(\mathrm{GPa})^{\mathrm{a}}$ \\
\hline As-received & $188 \pm 7^{b}$ & $7.1 \pm 0.5$ & $76 \pm 0.5$ \\
\hline As-received $+1: 2$ acid + dry and sinter & $68 \pm 23$ & $0 . \overline{5}$ & - \\
\hline As-received $+1: 10$ acid + dry and sinter & $126 \pm 12$ & $2.7 \pm 0.9$ & - \\
\hline As-received $+1: 10 \mathrm{P} / \mathrm{Al}+$ dry and sinter & $198 \pm 7$ & $5.1 \pm 0.7$ & $79 \pm 0.8$ \\
\hline Lab-made $+1: 10 \mathrm{P} / \mathrm{Al}+$ dry and sinter & $205 \pm 7$ & $7.6 \pm 0.5$ & $77 \pm 0.5$ \\
\hline As-received $V_{\mathrm{f}}=20$ vol. $\%$ & $231 \pm 3$ & $4.2 \pm 0.9$ & $94 \pm 1$ \\
\hline Particle-infiltrated + dry and sinter $V_{\mathrm{f}}=20$ vol. $\%$ & $241 \pm 3$ & $5.7 \pm 0.6$ & $99 \pm 2$ \\
\hline
\end{tabular}

\footnotetext{
a Values are obtained from the resonant vibration method.
}

${ }^{\mathrm{b}}$ Errors are the $95 \%$ confident limits deduced from a Students ' $t$ ' distribution. 
mainly due to the extra alumina ( $\sim 2.5$ vol.\%). It is interesting however, to note that the strain at break of the hybrid MMC is also slightly higher than that of the fibre-only reinforced composite. Normally, the elongation of MMCs would decrease with increasing reinforcement volume fraction.

The relatively higher strain at fracture exhibited by the particle-modified MMC may be due to better compatibility between reinforcement and matrix. The existence of particles near the fibres may result in a gradient in the interfacial stress state, i.e. from aluminium matrix to a particle-reinforced region and then to the fibre. A number of studies [30,31] on particulate/ fibre or whisker hybrid MMCs concluded that the particulate/fibre (or whisker) ratio exerts a significant influence on the properties. Improved fracture toughness [30] and tensile strength [31] over the fibre-only reinforced MMCs were observed. Friend et al.'s work [30] suggested that by altering the particulate/fibre ratio, the toughness of the hybrid MMC can be continuously changed from the low value associated with short-fibre composites (at low particle/fibre ratios) to a higher value characteristic of particulate-reinforced materials (at high particle/fibre ratios).

\section{Conclusions}

Aluminium matrix composites have been fabricated by squeeze casting as-received and modified alumina fibre preforms. Attempts to create inter-fibre bonds by sintering were unsuccessful because the temperatures needed to achieve a strong inter-fibre bond caused fibre damage due to the phase transformation from $\delta$ - to $\alpha$-alumina and to grain growth. Temperatures below $1200{ }^{\circ} \mathrm{C}$ had little effect on the phase transformation but also very limited effect on the inter-fibre bonding.

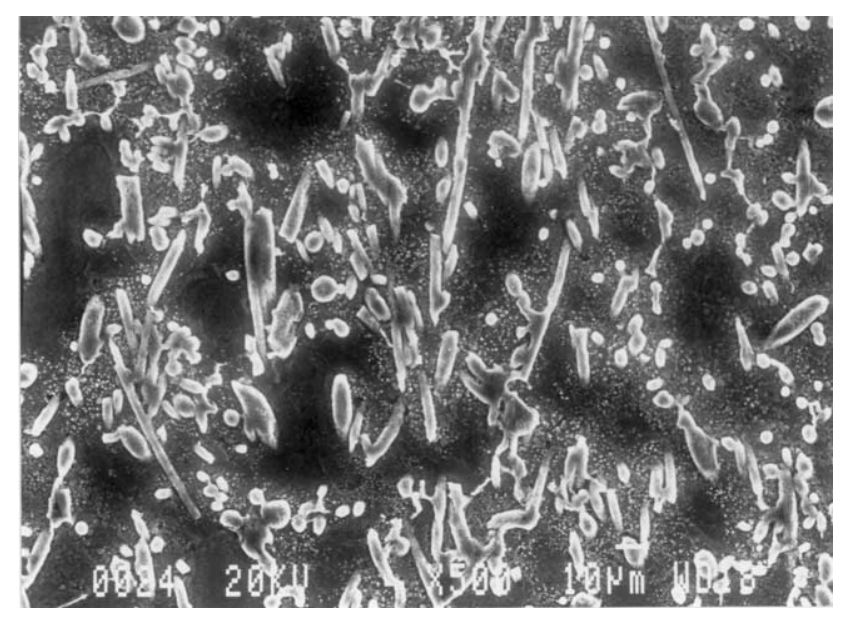

Fig. 10. The microstructures (transverse section of the cast cylinder) of the composites made from the preform $\left(V_{\mathrm{f}}=20 \%\right)$ infiltrated with a particle suspension.
The use of phosphoric acid as a binder produced aluminium phosphate by reaction between the acid and the fibre, but this sacrificed some of the fibre. The binder morphology was intact when sintered at $800{ }^{\circ} \mathrm{C}$ and this gave a 17 -fold increase in the preform strength relative to the unmodified preform. However, inter-fibre bonds created by using phosphoric acid alone gave very low composite strength and ductility due mainly to severe damage to the fibres caused by the chemical reaction. It implies that phosphoric acid alone cannot serve as a suitable binder for these preforms. In the present work, preform compressive strength offered no guide to composite strength.

Attempts were made to attach alumina particles onto the fibre surfaces. There was little sintering to the fibre surface at $1200{ }^{\circ} \mathrm{C}$ but composites made from these preforms showed more ductility.

By employing a stoichiometric mixture of phosphoric acid and aluminium hydroxide, a phosphate binder was produced that gave strong inter-fibre cross-links. Composites reinforced with the laboratory-made preform had higher tensile strength relative to the uniform fibre reinforced composites without any sacrifice to the ductility or in-plane elastic modulus.

\section{Acknowledgements}

The authors are grateful to EPSRC for the financial support of this work under Grant No. GR/L80553 and to Mr Barry Harvey of Vernaware, Bolton, UK for supplying the alumina fibre preforms.

\section{References}

[1] T.W. Clyne, P.J. Withers, An Introduction to Metal Matrix Composites, Cambridge University Press, Cambridge, 1997.

[2] B. Terry, G. Jones, Metal Matrix Composites, Elsevier, Oxford, 1990.

[3] J.M. Chiou, D.D.L. Chung, J. Mater. Sci. 28 (1993) 1435.

[4] B.L. Zhou, JOM (1994) 57.

[5] Y.T. Zhu, J.A. Valdez, I.J. Beyerlein, S.J. Zhou, C. Liu, M.G. Stout, D.P. Butt, T.C. Lowe, Acta Mater. 47 (1999) 1767.

[6] N. Phan-Thien, Fibre Sci. Technol. 14 (1981) 241.

[7] N. Phan-Thien, Fibre Sci. Technol. 15 (1981) 111.

[8] S. Fu, B. Zhou, C. Lung, Compos. Sci. Technol. 47 (1993) 245.

[9] S.Y. Fu, S.H. Li, S.X. Li, G.H. He, B.L. Zhou, C.W. Lung, Scr. Metall. Mater. 29 (1993) 1541.

[10] L.I. Salminen, V.I. Raisanen, M.J. Alava, K.J. Niskanen, J. Pulp Paper Sci. 22 (1996) J402.

[11] E. Retulainen, K. Ebeling, Appita J. 46 (1993) 282.

[12] R.A. Stratton, J. Pulp Paper Sci. 19 (1993) J6.

[13] K.J. Niskanen, M.J. Alava, E.T. Seppala, J. Astrom, J. Pulp Paper Sci. 25 (1999) 167.

[14] C. Askling, L. Wagberg, M. Rigdahl, J. Mater. Sci. 33 (1998) 1517.

[15] J.D. Birchall, N.McN. Alford, K. Kendall, J. Mater. Sci. Lett. 6 (1987) 1456. 
[16] J.E. Lyon, T.U. Fox, J.W. Lyons, Am. Ceram. Soc. Bull. 45 (1966) 661.

[17] W.H. Gitzen, L.D. Hart, G. Maczura, Am. Ceram. Soc. Bull. 35 (1956) 217.

[18] Z. Fan, P. Taakiropoulos, A.P. Miodownik, Mater. Sci. Technol. 8 (1992) 922.

[19] Z. Fan, A.P. Miodownik, Acta Metall. Mater. 41 (1993) 2403 (see also p. 2415).

[20] Z. Fan, Philos. Mag. 73 (1996) 1663.

[21] H.X. Peng, Z. Fan, J.R.G. Evans, J. Microsc. 201 (2) (2001) 333.

[22] H.X. Peng, Z. Fan, J.R.G. Evans, J. Mater. Sci. 36 (2001) 1007.

[23] Student Manual for Strain Gage Technology, Bulletin 309D, Measurement Group UK Ltd, Basingstoke, Hampshire, 1993, p. 17.
[24] J.D. Birchall, J.A.A. Bradburg, J. Dinwoodie, Strong Fibres. In: Handbook of Composites, vol. 1, North-Holland, Amsterdam, 1988, p. 115.

[25] J. Dinwoodie, SAE Technical Paper Series, No. 870437, 1987.

[26] J.M. Chiou, D.D.L. Chung, J. Mater. Sci. 28 (1993) 1471.

[27] T. Komori, K. Makishima, Text. Res. J. 47 (1977) 12.

[28] C. Toy, O.J. Whitemore, Ceram. Int. 15 (3) (1989) 167.

[29] I.J. Beyerlein, Y.T. Zhu, S. Mahesh, Compos. Sci. Technol. 61 (2001) 1341.

[30] C.M. Friend, I. Horsfall, C.L. Burrows, J. Mater. Sci. 26 (1991) 225.

[31] G. Wu, N. Kono, H. Watanabe, T. Takahashi, Scr. Metall. Mater. 28 (1993) 683 